\title{
Philosophy with Children within Social Network Sites: Engaging Towards a Virtual Community
}

\author{
Iulia MEDVESCHI, PhDc \\ Department of Communication, Public Relations and Advertising \\ Faculty of Political, Administrative and Communication Sciences \\ Babeş-Bolyai University, Cluj-Napoca, Romania \\ E-mail: medveschiiulia@yahoo.com
}

Assoc. prof. Mihaela FRUNZĂ, PhD

Department of Communication, Public Relations and Advertising Faculty of Political, Administrative and Communication Sciences Babeş-Bolyai University, Cluj-Napoca, Romania

E-mail: mihafrunza@gmail.com

Lect. Iulia GRAD, PhD

Department of Communication, Public Relations and Advertising Faculty of Political, Administrative and Communication Sciences Babeş-Bolyai University, Cluj-Napoca, Romania

E-mail: grad@fspac.ro

\section{Ariana GUGA, PhDc}

Department of Communication, Public Relations and Advertising Faculty of Political, Administrative and Communication Sciences Babeş-Bolyai University, Cluj-Napoca, Romania

E-mail: ariana.guga@yahoo.com

Abstract. The objective of this article is to discuss the benefits offered by the Philosophy with Children program with roots in the Socratic method, in which the individuals reach their own conclusions by exercising the dialectics. In the second part, we aim to highlight the set of pedagogical 
practices used within the activities of a Philosophy with children club. The meetings are designed in order to cultivate pupils' conscious and volitional forms of motivation and self-regulated learning in school and beyond. Ultimately, we will reiterate the constructive role of social network sites and social media phenomena in promoting and spreading the important social and co-operative experiences that develop listening, empathy, respect, friendship and the ability to truly work and think co-operatively.

Keywords: Philosophy; Children; Club, Community of inquiry; Virtual community; Social media.

\section{Introduction}

Philosophy with children is an educational field that provides children with appropriate instruments as they begin to question the world and their own insertion in it. It is a systematic and progressive program specially designed for them. The program is based on traditional topics in the history of Philosophy, and through a set of methodological guidelines, carefully planned and implemented, which nurture the curiosity and wonder of children, it aims to stimulate and develop complex thinking within a community of inquiry. In this type of community, the members work to be able to understand the point of view of others and strive in solidarity to discover the meaning of the world and the society in which they live. This article aims to highlight the benefits of applying philosophy with children, at the same time pointing towards a series of communicational strategies used to promote a Philosophy with children Club on social media networks.

\section{The philosophy with Children Club?}

The project "Philosophy with Children Club" is an initiative of a group of teachers from Babeş-Bolyai University in Cluj-Napoca, a group composed of Associate professor PhD Mihaela Frunză from the Department of Philosophy, Faculty of History and Philosophy, Assist. PhD Iulia Grad, and respectively PhD candidates Ariana Guga and Iulia Medveschi (the latter ones studying at the Doctoral School of the Department of Communication, Public Relations and Advertising at the Faculty of Political, Administrative and Communication Sciences). The project aims to introduce Philosophy with Children in cultural and educational institutions in Romania and to develop partnerships with similar institutions from Romania and abroad.

The Philosophy for Children programs (P4C) draw their inspiration from the life-time activity of professor Matthew Lipman in the 1970s from the US, and the subsequent developments from the European space, in the 1990s. Currently, this 
discipline is studied in more than 60 countries. In this respect, P4C should be understood as "the attempt to construct a pedagogical tool that functions as a model for critical thinking by describing 'real life' children engaged in critical dialogue about philosophical issues, with the goal of stimulating the same sort of dialogue among groups of students" (Vansieleghem, Kennedy 2011, 173).

In a constantly changing society, Van der Leeuw advocates for an educational system which pledges for reflexive thinking and communication. According to his perspective through philosophy "we expect people to be able to reflect rationally on human life, which includes a view of reality, of the place of the individual in society, of values and norms, of the meaning of life and so on. [And] ... we expect them to be able to communicate these views to others, because we live in a common reality, and this common reality must be the subject of common discourse, and can even be regarded as a common construct (Van der Leeuw 2009, 113).

The introduction of philosophy as an object of study for several generations of children in learning systems in New Zealand, Australia, Canada, or the UK has shown that this way of engaging philosophical thinking skills, from a young age, has generated a large number of assertive kids endowed with independent thinking, able to relate critically-constructive to knowledge, to articulate and conceptualize their ideas and to think independently and creatively, to be tolerant towards the ideas of others, and ultimately, to work in innovative communities of people with similar thinking. Undoubtedly, this kind of philosophical meetings can help children develop their patience, contentment, confidence in their own strengths, and also to realize their own weaknesses, "prioritizing values such as respect and subjectivity related to personal experience" (Daniel, Auriac 2011, 421).

The Philosophy with Children Club aims to involve pupils aged between 7 and 12 in reflection and philosophical exploration through a set of specific methods of stimulating and encouraging the curiosity of children, all of which help them to look for meanings, to cultivate intellectual courage, and to make fair judgments in everyday life.

In the club's activities, children are helped to identify philosophical themes through children stories. In our meetings, we follow the suggestions of Thomas E. Wartenberg's book, "Big Ideas for Little Kids". Subsequently, various philosophical concepts and theories (the Allegory of the Cave, the veil of ignorance, etc.) are introduced using non-formal methods (discussions, role play, film watching). Most of the exercises are adapted from the book "The Philosophy Club, An Adventure in Thinking", by Roger Sutcliffe and Steve Williams, on the website www. p4c.com as well as from the book of David A. White "Philosophy for Children. Your curiosities about the world". We use many times group discussions, given the fact that philosophy for children is a practice of collective investigation.

In order to distinguish what we do from the general mainstream approach of P4C, we have labeled our methods Philosophy with Children. We believe that 
children stories are more than mere stimuli, and this is why we do not use this psychological terminology when we refer to the tools that are used. Moreover, philosophy with children is specifically concerned with teaching children philosophy, not other subjects, whereas traditional P4C can be embedded as a method for teaching all kinds of scholarly disciplines. This is why we incorporate philosophical concepts and sometimes light versions of philosophical theories in our lessons (which mainstream P4C generally does not approve of).

Philosophy with children possesses the "means of increasing the potential power of children (who are defined as essentially vulnerable) in order to neutralize unequal power relations by strengthening processes of communication and cooperation" (Vansieleghem, Kennedy 2011, 177). Therefore, the introduction of philosophy as an object of study from a very young age is important, as it gives children a fundamentally different attitude towards learning and to knowledge, in general, towards diversity and alterity. In fact, the main message of the practice of philosophizing in children's study communities is that answers are neither definitive nor unique, but rather that at different times some can be reasonably stronger than others.

Philosophical investigation is a forceful practice that gives children the opportunity to ask questions and explore issues, concepts and ideas that are important and relevant to their life regardless of (and adapted to) their age. "Philosophical questions are presented to children in an intimate way; their philosophical questioning is at once highly practical (in the sense that these questions are asked earnestly in an attempt to develop a better understanding of the world, and in the same time, profoundly, playful" (Lone, Burroughs 2016, 9).

The object of the philosophy with children includes those common, central and challenging concepts that both underlie our life experience and that of academic discipline. In our meetings we discuss concepts such as: truth, freedom, justice, rights, identity, friendship, rules, language, thinking. These are topics that philosophy deals with and which children like to discuss. They can be helped to identify these ideas and concerns in stories, novels or children's films.

The central pedagogical tool of philosophy with children is the community of inquiry built around a stimulus represented by a story or a wide range of other resources such as images and records. In this type of community, children work together to generate questions, to search for answers and to discuss them. The community of inquiry "reflects democracy and initiates the children into the principles and values of this paradigm, it engages young generations in a process of individual growth ... By exercising in school freedom of thought and action, democracy will become their way of living and being when they become active adults within their society" (Sharp 1999, 12).

Discussions with children in communities of inquiries are not mere exchanges of views but are aimed at building the best answer to the questions raised, and the 
best answers are not provided or validated by the educator. Instead, the class is responsible for building and evaluating the range of possible answers to a question. Within the group, each individual learns to express their own ideas while taking into account different perspectives. Philosophy with Children "points that a central tenet of character education focuses only on cognitive development providing an insufficient basis for real moral development, which requires the development of affection and action alongside cognition" (Peterson, Bentley 2015, 53). Philosophy with children is not based on the assumption that there are right or wrong answers, but on the belief that, even if final answers are difficult or impossible to find, some can reasonably be more solidly defended than others. Tolerance, the ability to work constructively together, and the ability to explore, construct, express and conceptualize thoughts and ideas are the main results that both individuals and societies need with their larger-age educational systems to be as functional as possible, innovative and quickly adaptable to the continuing challenges they face at an accelerated pace.

\section{Social media and the online community of philosophy with children supporters}

As today we live not only in the physical but also in a virtual world, geographic boundaries and cultural barriers are constantly shifting. The Internet, from its simple functionality, has become a new way of processing, presenting and communicating information which allows the implementation of new models and concepts. At the same time, it offers access to multimedia presentations including images, text, animations and sounds in the same entity. To accommodate the increasing demand for relevant online content, we have built a Facebook page for The philosophy with children club: www.facebook.com/Club-de-filosofie-cu-copiii282832722087827/. We aimed it to serve as an interest-focused conversational hub that brings together people based on shared interest. At present, the Philosophy for Children Club page is a micro-community, bringing together 273 supporters (people with similar concerns and motivations). Another instrumental reason for designing it was that it helped us gathering the supporters of philosophy with children for obtaining financial support to open another venue for the Club ${ }^{1}$.

When we designed the page, we departed from the observation that any attempt to define virtual communities meets a number of major difficulties. It is obvious that, both in essence and in the ways of manifestation, virtual communities

1 The online campaign to promote the Philosophy for Children Club project took place for three weeks, during 18 August - 7 September 2016 through social media. Given that the winners of the Comm'ON Cluj Competion were selected counting the votes gathered via Facebook, the page facilitated the interaction and recognition of Facebook users. 
can not fit precisely into the definitions of classical social communities. Starting from the idea of Robert Plant, "the online community can be defined as a collective group of entities, people who come together, either temporarily or permanently, through electronic support to interact with a common problem or interest". (Plant 2004, 54). In short, the established community has access to a continuous view with the help of spontaneous images uploaded to a collaborative media space. According to Rheingold, the notion of virtual community is not to be dismissed as a technological, cyberpunk fantasy in which people are increasingly chained to their computer terminals, experiencing life through dehumanizing. Instead, Rheingold defines virtual communities as "social aggregations that emerge from the [Internet] when enough people carry on those public discussions long enough, with sufficient human feeling, to form webs of personal relationships in cyberspace" (Rheingold 1993, 5).

We used Rheingold (1993) insights when we designed our campaign. We have also take into account the following advantages of online communication, given that online visibility is increasing in comparison to traditional communication channels (posters, print media):

- It enables faster and easier dissemination of relevant information;

- It eases the quantification of the number of people viewing and interacting with the information (by commenting or sharing it);

- It gives the chance of adopting more creative ways of presenting the message;

The Facebook Page - Philosophy with Children Club helps to establish a new form of collective identity (bringing together supporters of children's philosophy). The sharing of written and visual content plays a crucial role in cultivating a sense of belonging to a collective identity. In this direction, a community was set up to disseminate the information related to the promotion of the initiative - The Adventure of Thinking enrolled in the Com'ON Cluj 2016 competition, the photo collages from the philosophical meetings, as well as the articles advocating the necessity of the philosophy for children.

\section{Objectives to create relationships with the public}

More than any other activities in the marketing mix, through the public relations strategies we have set ourselves close to our audience as initiators of the project on Facebook social networking through a conscious, planned and sustained effort. Effective communication is the name for such planned communication campaigns. Public relations are "a management function that classically focuses on long term patterns of interaction between an organization/project and all of its various publics, both supportive and non--supportive. Public relations seek to enhance these relationships, thus generating mutual understanding, goodwill and support" (Smith 2005, 4). 
According to Popescu, "continuous communication techniques are those elements that are stable throughout the life cycle of the product / service that ensures uninterrupted communication with your target audience concerned. The most important continuous communication techniques are brand, design and packaging, the architectonics" (Popescu 2002, 116). The online environment is good environment for creating connections between people, cultivating and developing them. This relationship is scheduled in the long run, because, given the existence of credibility built over time, it can bring benefits to our project. Specifically, the collaboration with our public can take the form of discussions on the Facebook page of the project, discussions in groups that advocate in favor of children's philosophy, the initiation of possible collaborations and the extension of children's philosophy projects for children at the national level, etc.

\section{Objectives to increase notoriety}

The online environment has become the favorite source of information for people because it still has credibility. Our Facebook page leaves room for comments, the contribution of the audience we are addressing.

The publics we are addressing through the page:

- Parents from Cluj-Napoca;

- Children aged between 7 and 12 years old;

- Teachers from Cluj-Napoca;

- The local community interested in non-formal educational projects.

\section{Communication strategies used between August and September 2016}

To highlight the benefits of philosophy for/with children, the first strategy used was to post messages to more than 30 local groups, using concrete, familiar words that refer to tangible objectives. Words are powerful - they carry a literal as well as a connotative meaning. Among the messages that encouraged the voting of a philosophy project for children, we mention: "Little detectives of the mind: they have the possibility to discover the secrets of the mind through philosophical questions!", "Mind gymnastics: Philosophical apprentices can give power to their ideas through exercises and games!" "Flexible and original thinking!". These words "are more likely to maintain your audience's interest and less likely to be misinterpreted in a competitive environment positioning the project according to its own particular niche" (Smith 2005, 70).

Moving forward, the second strategy that has given visibility to our initiative includes publishing articles on different platforms - online and offline - in this way casting interest and gathering votes. Here we mention the Welcome2Cluj blog, the blog of Rareş Iordache and the blog of the Seminary of Interdisciplinary 
Research of Religions and Ideologies. A third successful strategy focused on posting pictures of project proponents - in principle, the supporters working in the “Octavian Goga" County Library, ClujNapoca.

Finnally, the fourth strategy was based on the use of the hashtag tool - \# - \#philosophyforkids, \#clubfilofoffices \#comoncluj \#shareitforward They helped us to: 1. increase awareness - our initiative has reached people who have discovered the project by chance, seeking to document themselves about the topics relevant to them. In this way, we also encouraged interaction with our target audience, the latter supporting the campaign by promoting the above mentioned hashtags. They were beneficial for launching the campaign for supporting Children's Philosophy, the dissemination of the news related to the project, and the 8 meetings to be held at the "Traian Brad" Mănăştur Branch affiliated to"Octavian Goga" County Library Cluj-Napoca.

Although the subject of philosophy for children did not seem quite popular to mobilize voters, and in particular to compete with other initiatives such as parties, dance classes, acting workshops, coherent and consistent communication strategies have counterbalanced the situation in favor of our project.

This project was gradually launched in the online environment as a parent awareness campaign, highlighting that philosophy helps children think, consequently, helping them to improve their school performances. In addition, children can be seen as born-philosophers because they have an overwhelming curiosity and see the world with a fresh look. The aim "is not to turn children into philosophers or decision makers, but to help them become more thoughtful, more reflective, more considerate, and more reasonable individuals. Children who have been helped to become more judicious not only have a better sense of when to act but also of when not to act" (Lipman et al. 1980, 15).

Quite often, we find ourselves in difficulty with questions that keep busy both scientists and philosophers: "Why do we work?", "How do you know who you are?", "What is courage?", etc. At first glance, we might think that just having a solid knowledge of philosophy, an adult can have philosophical discussions with a child. But in a philosophical discussion it is important to open and conduct the discussion, not to provide answers or theories. "Dialogue as a form of speech inherently resists the reification of ideas or practices and trades instead on clarifying essences, postponing judgments, working with ambiguities and interrogating assumptions, these being achieved through dyadic or group deliberation" (Vansieleghem, Kennedy 2011, 176). The purpose of the discussion is to guide the child into formulating his own ideas and opinions, to complex subjects, for which we do not always have a clear or generally accepted answer. 


\section{Conclusion}

As a foregone conclusion, philosophy with children could be understood as a mental exercise through intellectual challenges. Philosophical reunions are designed on a fourth scale scheme: 1. Encouraging questions, 2. Advocating for a collaborative concept development, 3. encouraging dialogue and argumentation, 4. Maintaining the formation of reasonable attitude. Through the online activity, the benefits of philosophy with children are outlined on three levels: 1 . Self-esteem in learning situations - children participating in the club, at free-lance discussions, show a higher self-esteem as students. In other words, children feel more confident in their own learning ability as a potential way of cultivating students' conscious and volitional forms of motivation and self-regulated learning in school and beyond; 2. Critical thinking and communication - participation in the activities of the philosophy club, doubles the situations in which children use arguments to support their ideas, with the need to focus on the frequent use of open questions; 3. Emotional and social development - Children improve their communication skills and their ability to focus attention. It is also possible through group activity to help children to better manage their emotions, to capitalize on the opinions of others, even if they are different. The cultivation of awareness and willful self-regulation are preconditions for deep learning, freedom of thought, creativity, harmonious social relationships.

\section{References}

1. Daniel, M. F, Auriac, E. (2011). Philosophy, Critical Thinking and Philosophy for Children, Educational Philosophy and Theory, 43(5), 415-435. doi: 10.1111/j.14695812.2008.00483.x

2. Lipman, M., Sharp, A. \& Oscanyan, F. (1980). Philosophy in the classroom. Philadelphia, PA: Temple University Press.

3. Lone, J.M, Burroughs, M. (2016). Philosophy in Education. Questioning and Dialogue in Schools, London: Rowman\&Littlefield.

4. Peterson, A, Bentley, B. (2015). Exploring the connections between Philosophy for Children and character education: Some implications for moral education?, Journal of Philosophy in Schools, 2(2). 48-70.

5. Plant, R. (2004). Online Communities, Technology in Society, 26, 51-65.

6. Popescu, I, C (2002). Comunicareaînmarketing :concepte, tehnici, strategii, Bucharest: Uranus Publishing House.

7. Rheingold, H. (1993). The Virtual Community: Homesteading on the Electronic Frontier. New York: Addison-Wesley.

8. Sharp, AM (1999). The sacred-as-relationship in the community of inquiry. Paper presented at the Philosophy for children on top of the world: Proceedings of the 
8th International Conference on Philosophy with Children, Iceland, University of Akureyri Research Fund. 5-19.

9. Smith, R. D. (2005). Strategic Planning for Public Relations, Malawah, New Jersey: Lawrence Erlbaum Associates, Publishers.

10. Van der Leeuw, K. (2009). Philosophy for Children as Educational Reform, in: E. Marsal, T. Dobashi and B. Weber (eds) Children Philosophize Worldwide. Theoretical and Practical Concepts (New York, Peter Lang), pp. 117-126.

11. Vansilieghem, N, Kennedy, D. (2011). What is Philosophy for Children, What is Philosophy with Children - After Matthew Lipman?.Journal of Philosophy of Education, 45(2), 171-182. 